\title{
Study of drug resistance pattern among isolated strains of Mycobacterium tuberculosis against individual antimycobacterial drugs
}

\author{
Kashetty V. ${ }^{1 *}$, Ghatole M. $^{2}$, Ghule A. ${ }^{3}$ \\ DOI: https://doi.org/10.17511/jopm.2020.i04.03 \\ 1* Virendra Kashetty, Associate Professor, Department of Microbiology, Ashwini Rural Medical College Hospital and Research Centre, \\ Solapur, Maharashtra, India. \\ 2 Mangala Ghatole, Professor, Department of Microbiology, Ashwini Rural Medical College Hospital and Research Centre, Solapur, \\ Maharashtra, India. \\ ${ }^{3}$ Apeksha Ghule, Assistant Professor, Department of Microbiology, Ashwini Rural Medical College Hospital and Research Centre, Solapur, \\ Maharashtra, India.
}

Background: In the laboratory in-vitro antimycobacterial sensitivity testing is done conventionally by exposing the test strain to individual drugs by one of the recommended methods. Thus the present work was planned to assess the effects of various antimycobacterial drugs individually. Methods: The study included 73 strains of Mycobacterium tuberculosis isolated from 216 patients suffering from pulmonary tuberculosis and who visited the hospital for the first time and who had not received any antimycobacterial chemotherapy. From all these patients early morning spot sample was collected in a wide-mouthed sterile container and transported immediately to the laboratory. Result: Out of 73 stains, 62 (84.93\%) were sensitive to all primary antimycobacterial agents and $11(15.07 \%)$ were resistant to one or more drugs. $6(8.22 \%)$ were resistant to Isoniazid (INH), $9(12.33 \%)$ and $2(2.74 \%)$ strains were resistant to Rifampicin (R'cin) and Streptomycin respectively. Overall resistance to a single drug was higher (8.22\%) than to two drugs $(5.48 \%)$ followed by three drugs $(1.37 \%)$. Conclusion: Treatment of tuberculosis with appropriate drugs for a defined period is an important factor in the complete remission of disease in the individual patient, as well as in the management of the disease in a community.

Keywords: Mycobacterium tuberculosis, Antimycobacterial drugs, Pulmonary Tuberculosis, Resistant

\section{Corresponding Author}

Virendra Kashetty, Associate Professor, Department of Microbiology, Ashwini Rural Medical College Hospital and Research Centre, Solapur, Maharashtra, India.

Email: vkashetty@rediffmail.com
How to Cite this Article

Kashetty V, Ghatole M, Ghule A. Study of drug resistance pattern among isolated strains of Mycobacterium tuberculosis against individual antimycobacterial drugs. Trop J Pathol Microbiol. 2020;6(4):284-291.

Available From

https://pathology.medresearch.in/index.php/jopm/ar ticle/view/456
To Browse

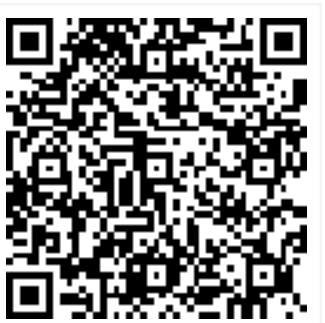

Manuscript Received 07-04-2020

Conflict of Interest No 


\section{Introduction}

Every year, about 9 million people suffer from active tuberculosis, and about 2 million die because of this disease [1].

According to the World Health Organization and other international studies stated that the resistance against antituberculosis antibiotics exists all around the world, and the global prevalence of primary resistance is almost $10.7 \%[1,2]$.

The first clinically drug-resistant tuberculosis case was not described until 1970 [3]. There have been reports from various parts of India [3-5] and some parts of the world [6] regarding recent outbreaks of MDR-TB.

India accounts for $1 / 3$ rd of the global tuberculosis burden. It has more tuberculosis cases than any other country in the world and twice as many patients on treatment as China which has the next highest number [7]. Every year 18 lakhs people develop tuberculosis.

Each infectious patient can infect 10 to 15 persons in a year unless effectively treated. The tuberculosis burden is compounded by an estimated 4.58 million HIV infected persons living in India [8].

Thus, it can be understood that tuberculosis treatment with appropriate drugs is the backbone of the Tuberculosis Control Programme.

In Tuberculosis Control Programme antituberculosis drugs are given in combination with two or more drugs to reduce the duration of therapy and to prevent toxicity and emergence of drug resistance.

In the laboratory in- vitro antimycobacterial sensitivity testing is done conventionally by exposing the test strain to individual drugs by one of the recommended methods. Thus the present work was planned to assess the effects of various antimycobacterial drugs individually.

\section{Objectives}

01. To identify isolated strains of Mycobacteria from sputumsamples collected from pulmonary tuberculosis cases.

02. To determine the drug resistance pattern among isolated strains of Mycobacterium tuberculosis against individual drugs like Streptomycin, Isoniazid, Rifampicin, and Ethambutol.

\section{Material and Methods}

The present study was carried out in the department of microbiology in collaboration with the district tuberculosis center at Shri Chhatrapati Shivaji Maharaj Sarvopachar Rugnalaya, Solapur, Maharashtra, India for two years. The sample size of the present study was calculated according to the formula,

$N=Z 2 p(1-p) / d 2[9]$

The study included 73 strains of Mycobacterium tuberculosis isolated from 216 patients suffering from pulmonary tuberculosis and who visited the hospital for the first time and who had not received any antimycobacterial chemotherapy. From all these patients early morning spot sample was collected in a wide-mouthed sterile container and transported immediately to the laboratory of Department. of Microbiology.

Processing- All the samples were decontaminated and concentrated by Petroff's method [10]. Then the deposits were used for processing, smear preparations, and cultures.

Microscopy- From the deposit one loopful of the deposit was smeared on a new, clean, grease-free slide and stained with Ziehl Neelsen stain. Then the smear was examined with oil immersion under a microscope for detection of AFB and grading was done according to the grading system recommended by RNTCP [11].

01. Inoculation on LJ medium: Before proceeding to culture an initial quality control check-up of all media was done using control strains of H37RV and five stock cultures of Mycobacterium tuberculosis isolated in the laboratory.

By using new swab culture method sputum samples were inoculated on Lowenstein Jensen (LJ) medium in duplicate and incubated at $370 \mathrm{C}$ till the appearance of visible growth of mycobacterium appears or maximum up to 8 weeks.

The day of the appearance of growth was noted. The colony characters i.e. color, size, consistency, pigment if any, and number were noted. Then colony smear was prepared and stained with Ziehl Neelsen to confirm acid-fast bacilli (AFB).

02. Identification: Each isolate was identified by using colony characteristics, rate of growth, the study of pigments, sensitivity to paranitrobenzoic acid, and biochemical tests. 
03. Antibiotic sensitivity testing: Antimycobacterial sensitivity testing was carried out by incorporating the various drugs (Viz. Ionized, Rifampicin, Streptomycin, and Ethambutol) in LJ medium. The sensitivity testing was done by using the Minimum Inhibitory Concentration (MIC) method for INH, Rifampicin, and Ethambutol and Resistance Ratio (RR) method

For Streptomycin $[12,13]$. The present study carried out antimycobacterial susceptibility testing by using the individual drug.

\section{A) Antimycobacterial Sensitivity testing by using the individual drug}

A) Media Preparation: For different antibiotics, various concentrations of drugs were incorporated into the LJ medium and inspissated.

1) Isoniazid (INH): The drug concentrations used for Isoniazid sensitivity testing were $5 \mu \mathrm{gm} / \mathrm{ml}$, $1 \mu \mathrm{gm} / \mathrm{ml}, 0.5 \mu \mathrm{gm} / \mathrm{ml}$ and $0.25 \mu \mathrm{gm} / \mathrm{ml}$.

To achieve these concentrations following dilutions were made.

$5 \mathrm{mgm}$ of $\mathrm{INH}+10 \mathrm{ml} \mathrm{D.W}$.

-------- $(0.5 \mathrm{mgm} / \mathrm{ml})$

$1 \mathrm{ml}$ of $0.5 \mathrm{mgm} / \mathrm{ml} \mathrm{INH}$ solution $+4 \mathrm{ml} \mathrm{D.W.-------}$

------- $(0.1 \mathrm{mgm} / \mathrm{ml})$

$3 \mathrm{ml}$ of $0.1 \mathrm{mgm} / \mathrm{ml} \mathrm{INH}$ solution $+3 \mathrm{ml} \mathrm{D.W.} \mathrm{------}$ ------ $(0.05 \mathrm{mgm} / \mathrm{ml})$

$4 \mathrm{ml}$ of $0.05 \mathrm{mgm} / \mathrm{ml}$ INH solution $+4 \mathrm{ml} \mathrm{D.W.} \mathrm{-----}$ $----(0.025 \mathrm{mgm} / \mathrm{ml})$

By adding $0.5 \mathrm{ml}$ of these solutions in $50 \mathrm{ml}$ of plain LJ medium, the current study achieved the desired concentrations of INH in the medium.

2) Ethambutol (E): The drug concentrations used for Ethambutol sensitivity testing were $32 \mu \mathrm{gm} / \mathrm{ml}$, $16 \mu \mathrm{gm} / \mathrm{ml}, 8 \mu \mathrm{gm} / \mathrm{ml}$ and $4 \mu \mathrm{gm} / \mathrm{ml}$.

To achieve these concentrations following dilutions were made.

$16 \mathrm{mgm}$ of $\mathrm{E}+5 \mathrm{ml} \mathrm{D.W}$.

-----(3.2 $\mathrm{mgm} / \mathrm{ml})$

$2 \mathrm{ml}$ of $3.2 \mathrm{mgm} / \mathrm{ml}$ E solution $+2 \mathrm{ml} \mathrm{D.W}$.

--- $(1.6 \mathrm{mgm} / \mathrm{ml})$

$2 \mathrm{ml}$ of $1.6 \mathrm{mgm} / \mathrm{ml}$ E solution $+2 \mathrm{ml} \mathrm{D.W}$.

--- $(0.8 \mathrm{mgm} / \mathrm{ml})$

$2 \mathrm{ml}$ of $0.8 \mathrm{mgm} / \mathrm{ml}$ E solution $+2 \mathrm{ml} \mathrm{D.W}$.

$---(0.84 \mathrm{mgm} / \mathrm{ml})$
By adding $0.5 \mathrm{ml}$ of these solutions in $50 \mathrm{ml}$ of plain LJ medium, the current study achieved the desired concentrations of Ethambutol in the medium.

3) Streptomycin (S): The drug concentrations used for Streptomycin sensitivity testing were $64 \mu \mathrm{gm} / \mathrm{ml}, 32 \mu \mathrm{gm} / \mathrm{ml}, 16 \mu \mathrm{gm} / \mathrm{ml}$ and $8 \mu \mathrm{gm} / \mathrm{ml}$.

To achieve these concentrations following dilutions were made.

$32 \mathrm{mgm}$ of $\mathrm{S}+5 \mathrm{ml} \mathrm{D.W}$.

$-(6.4 \mathrm{mgm} / \mathrm{ml})$

$2 \mathrm{ml}$ of $6.4 \mathrm{mgm} / \mathrm{ml} \mathrm{S}$ solution $+2 \mathrm{ml} \mathrm{D.W}$.

(3.2 $\mathrm{mgm} / \mathrm{ml})$

$2 \mathrm{ml}$ of $3.2 \mathrm{mgm} / \mathrm{ml} \mathrm{S}$ solution $+2 \mathrm{ml} \mathrm{D.W}$.

$(1.6 \mathrm{mgm} / \mathrm{ml})$

$2 \mathrm{ml}$ of $1.6 \mathrm{mgm} / \mathrm{ml} \mathrm{S}$ solution $+2 \mathrm{ml} \mathrm{D.W}$.

$(0.8 \mathrm{mgm} / \mathrm{ml})$

By adding $0.5 \mathrm{ml}$ of these solutions in $50 \mathrm{ml}$ of plain LJ medium, the current study achieved the desired concentrations of Streptomycin in the medium.

4) Rifampicin ( $R$ ): The drug concentrations used for Rifampicin sensitivity testing were $128 \mu \mathrm{gm} / \mathrm{ml}$, $64 \mu \mathrm{gm} / \mathrm{ml}, 32 \mu \mathrm{gm} / \mathrm{ml}$ and $16 \mu \mathrm{gm} / \mathrm{ml}$. To achieve these concentrations following dilutions were made.

$64 \mathrm{mgm}$ of $\mathrm{R}+5 \mathrm{ml}$ Alcohol

-----(12.8 $\mathrm{mgm} / \mathrm{ml})$

$2 \mathrm{ml}$ of $12.8 \mathrm{mgm} / \mathrm{ml} \mathrm{R}$ solution $+2 \mathrm{ml}$ Alcohol ---------(6.4 mgm/ml)

$2 \mathrm{ml}$ of $6.4 \mathrm{mgm} / \mathrm{ml} \mathrm{R}$ solution $+2 \mathrm{ml}$ Alcohol ---------- $(3.2 \mathrm{mgm} / \mathrm{ml})$

$2 \mathrm{ml}$ of $3.2 \mathrm{mgm} / \mathrm{ml} \mathrm{R}$ solution $+2 \mathrm{ml}$ Alcohol ----------(1.6 $\mathrm{mgm} / \mathrm{ml})$

By adding $0.5 \mathrm{ml}$ of these solutions in $50 \mathrm{ml}$ of plain LJ medium, the current study achieved the desired concentrations of Rifampicin in the medium.

01. Standardization of inoculums: Standardization of the size of the inoculum is important and depends on estimating the amount of growth on the media. With a 22SWG2 (Wire diameter 0.7) nichrome wire loop, a representative sweep from the growth was taken on the loop with a volume of $2 \mathrm{~mm} 2$ (approx. $2 \mathrm{mg}$ moist weight of the bacilli). The growth taken on the loop was then discharged in $0.4 \mathrm{ml}$ of D.W. contained in $0.25 \mathrm{cc} \mathrm{OZ}(7 \mathrm{ml})$ screw-capped bottles together with 6 glass beads ( $3 \mathrm{~mm}$ diameter). A suspension was 
Prepared by shaking the $7 \mathrm{ml}$ bottle for one minute on a mechanical shaker and then, with a $3 \mathrm{~mm}$ external diameter 27SWG (Wire diameter $0.4 \mathrm{~mm}$ ) nichrome loop. A loopful of the suspension was spread on the surface of each LJ slope for the sensitivity test.

02. Incubation and Interpretation of tests: The inoculated slopes were incubated at $370 \mathrm{C}$ and the media were observed on every alternate day. Preliminary results were observed after two weeks for sensitivity pattern, but the definitive reading was made at 4 weeks and a report that a strain was sensitive was not given earlier than 8 weeks. For all tests, 'growth' was defined as the presence of 20 or more colonies on the slope. If the control slope did not show satisfactory growth then that set of tests was repeated.

For Streptomycin, the resistance ratio was calculated as

MIC of the test strain

Resistance ratio $(\mathbf{R R})=$

MIC of H37 RV strain

Definition of resistance:

Sensitive - RR of less than 2

Resistance - RR of greater than 8

Doubtful - RR of 4

The doubtful test was repeated from the control slope, if the same reading was obtained, it was called as resistant.

Table-1: Criteria for resistance.

\begin{tabular}{|l|l|}
\hline \multicolumn{1}{|c|}{ Drugs } & \multicolumn{1}{c|}{ Criteria for Resistance } \\
\hline Isoniazid & MIC $>1 \mathrm{mg} / \mathrm{L}$ \\
\hline Rifampicin & MIC $>128 \mathrm{mg} / \mathrm{L}$ \\
\hline Ethambutol & MIC $>8 \mathrm{mg} / \mathrm{L}$ \\
\hline
\end{tabular}

\section{Result}

Table-2: Distribution of drug-sensitive and drug-resistant strains of $M$. tuberculosis to individual primary antimycobacterial agents viz. Isoniazid (I), Rifampicin (R), Ethambutol (E) and Streptomycin (S).

\begin{tabular}{|l|l|l|l|}
\hline & Sensitive to IRES & Resistant to one or more drugs & Total \\
\hline No. of strains & $62(84.93 \%)$ & $11(15.07 \%)$ & 73 \\
\hline
\end{tabular}

Out of 73 strains, 62 (84.93\%) were sensitive to all primary antimycobacterial agents and 11 (15.07\%) were resistant to one or more drugs.
Table-3: Distribution of drug-resistant strains of $M$. tuberculosis to individual primary antimycobacterial agents.

\begin{tabular}{|l|l|l|l|l|}
\hline $\begin{array}{c}\text { Antimycobacterial } \\
\text { agents }\end{array}$ & \multicolumn{1}{|c|}{ INH } & \multicolumn{1}{|c|}{$\mathbf{R}^{\prime}$ cin } & $\begin{array}{r}\text { Ethambut } \\
\text { ol }\end{array}$ & \multicolumn{1}{c|}{$\begin{array}{c}\text { Streptomyci } \\
\mathbf{n}\end{array}$} \\
\hline No. of Resistant strains & $\begin{array}{l}6 \\
(8.22 \%)\end{array}$ & $\begin{array}{l}\text { Nil } \\
(12.33 \%)\end{array}$ & $2(2.74 \%)$ \\
\hline
\end{tabular}

Out of 73 strains, $6(8.22 \%)$ were resistant to Isoniazid (INH), $9(12.33 \%)$ and $2(2.74 \%)$ strains were resistant to Rifampicin (R'cin) and Streptomycin respectively. No strain was resistant to Ethambutol.

Table-4: Distribution of drug-resistant strains of $M$. tuberculosis according to the overall resistance to single or multiple primary antimycobacterial drugs.

\begin{tabular}{|l|l|}
\hline \multicolumn{1}{|c|}{ Resistant to } & \multicolumn{1}{c|}{ No. of Resistant strains } \\
\hline One drug & $6(8.22 \%)$ \\
\hline Two drugs & $4(5.48 \%)$ \\
\hline Three drugs & $1(1.37 \%)$ \\
\hline All four drugs & Nil \\
\hline Total & $11(15.07 \%)$ \\
\hline
\end{tabular}

Overall resistance to a single drug was higher $(8.22 \%)$ than to two drugs $(5.48 \%)$ followed by three drugs (1.37\%).

Table-5: Pattern of drug resistance of $M$. tuberculosis strains which were resistant to the single primary antimycobacterial drug.

\begin{tabular}{|l|l|}
\hline \multicolumn{1}{|c|}{ Resistant to } & \multicolumn{1}{c|}{ No. of Resistant strains } \\
\hline I & $1(1.37 \%)$ \\
\hline R & $4(5.48 \%)$ \\
\hline E & Nil \\
\hline S & $1(1.37 \%)$ \\
\hline Total & $6(8.22 \%)$ \\
\hline
\end{tabular}

I - Isoniazid R - Rifampicin

E - Ethambutol S - Streptomycin

Out of 73 strains, $6(8.22 \%)$ revealed resistance to any one of the drugs. Resistance to Rifampicin was higher $(5.48 \%)$ than to Isoniazid and Streptomycin $(1.37 \%$ each). No single drug resistance to Ethambutol was noted.

Table-6: Pattern of drug resistance of $M$. tuberculosis strains which were resistant to two primary antimycobacterial drugs when tested individually.

\begin{tabular}{|l|l|}
\hline \multicolumn{1}{|c|}{ Resistant to } & \multicolumn{1}{c|}{ No. of Resistant strains } \\
\hline IR & $4(5.48 \%)$ \\
\hline IS & Nil \\
\hline
\end{tabular}




\begin{tabular}{|l|l|}
\hline RS & Nil \\
\hline Total & $4(5.48 \%)$ \\
\hline
\end{tabular}

$4(5.48 \%)$ strains revealed resistance to two drugs when tested individually. All these strains were resistant to Isoniazid as well as to Rifampicin.

Table-7: Pattern of drug resistance of $M$. tuberculosis strains which were resistant to three primary antimycobacterial drugs when tested individually.

\begin{tabular}{|l|l|}
\hline \multicolumn{1}{|c|}{ Resistant to } & \multicolumn{1}{c|}{ No. of Resistant strains } \\
\hline IRE & Nil \\
\hline RES & Nil \\
\hline ESI & Nil \\
\hline SIR & $1(1.37 \%)$ \\
\hline Total & $1(1.37 \%)$ \\
\hline
\end{tabular}

Only $1(1.37 \%)$ strain revealed resistance to three drugs when tested individually i.e. to Streptomycin, Isoniazid, and Rifampicin.

\section{Discussion}

Tuberculosis is responsible for high morbidity and mortality all over the world. In developing countries like India, it is one of the major health burdens for national policies. Few laboratories are equipped with facilities to perform culture and antimycobacterial susceptibility testing. Due to the emergence of multidrug-resistant strains, it is common for a clinician to come across treatment failure cases.

These cases may act as a source of infections leading to the spread of drug-resistant strains in a community. So, it is important to test the effects of individual antimycobacterial drugs of available antimycobacterial agents in the laboratory, so that an effective regiment cat is planned out in such cases.

The current study observed 73 M. tuberculosis strains, isolated from patients suffering from pulmonary tuberculosis who had not received any antituberculosis drug therapy in the past so that the primary resistant pattern of $M$. tuberculosis can be analyzed in patients attending our hospital. All these strains were isolated on Lowenstein Jensen (LJ) media and identified by colony morphology, PNB sensitivity, and biochemical tests.

As the prevalence of tuberculosis is very high in developing countries, the drug resistance pattern also differs in various countries. Initial drug resistance to one or more antituberculosis drugs is estimated to be 1 to $5 \%$ in European countries,
5 to $90 \%$ in Africa, 15 to $45 \%$ in Eastern Mediterranean, and 15 to $80 \%$ in South-East Asia $[14,15]$. While testing antimycobacterial sensitivity, the current study used first-line antimycobacterial agents viz. Isoniazid, Rifampicin, Ethambutol, and Streptomycin.

The current study observed that only 11 strains $(15.07 \%)$ were resistant to one or more primary drugs. These results are similar to the primary resistance pattern of $M$. tuberculosis observed by Kim et al in Korea (15\%) during 1990 [16]. Results of Koch $A$ et al have shown 15 to $80 \%$ of primary resistant tuberculosis in South-East Asia is consistent with our observations [14]. In contrast, Chattlet et al have shown a very low percentage of the initial $(10.9 \%)$ and primary $(8.2 \%)$ resistant $M$. tuberculosis in Algiers [17].

$12.33 \%$ of the strains showed resistance to Rifampicin, $8.22 \%$ of the strains were resistant to Isoniazid, whereas only $2.74 \%$ of the strains showed resistance to Streptomycin. The low resistance to Streptomycin may be explained on the basis of its infrequent use. All the strains were sensitive to Ethambutol. All our observations are within the Global drug resistance rates except Rifampicin (Isoniazid (0-16.9\%), Streptomycin (0.1$23.5 \%)$, and Ethambutol (0-4.3\%) (1).

The current study observed very high resistance to Rifampicin $12.33 \%$ as against $0.3 \%$ of the Global Drug Resistance Rate observed in India. This may be due to the increased use of Rifampicin containing antituberculosis regimens. This proposal is supported by the observation made by Jai NK et al in 1990 (60) that when Rifampicin use was limited its resistance was only $0.6 \%$ [18]. Now Rifampicin is used extensively in the regimens proposed to control tuberculosis, thus increasing the resistance to it.

The analysis of drug resistance pattern over 40 years by Tuberculosis Research Centre (162) also showed an increase in the drug resistance to Isoniazid from $3 \%$ in 1956 to $12 \%$ in 1974 and $13 \%$ in $1995,3 \%$ to Streptomycin in 1956 to $12 \%$ in 1974 $\% 13 \%$ in 1995 [13]. The observations about Rifampicin are very significant as no resistance was observed from 1956 to 1990 but from 1990 to 1995 $1.2 \%$ of the strains showed resistance. This period signifies the incorporation of Rifampicin in the National Tuberculosis Control Programme.

Resistance to Isoniazid and Rifampicin is important to define multidrug-resistance tuberculosis. WHO 
Defines multidrug-resistant tuberculosis, as the disease with organisms resistant to Rifampicin and Isoniazid with possible resistance to other drugs. Thus, by this definition $6.85 \%$ of our strains are multidrug-resistant. This is within the Global Multidrug-resistance Rate of 0 to $10.8 \%$ [19].

$8.22 \%$ of our strains were resistant to any one drug. M. tuberculosis acquires drug-resistance mainly through chromosomal mutations. Thus, it is a stepwise accumulation of individual mutations in several independent genes and not a- 'block' acquisition of multidrug-resistance. On this basis, these $8.22 \%$ strains are important, as they may develop multidrug-resistance in the future.

In the present study, none of the strains were resistant to all 4 primary antimycobacterial agents. Tuberculosis Research Control study comprising surveillance of drug-resistance tuberculosis has reported the overall resistance to anyone antituberculosis drugs to be from $12.7 \%$ to $34 \%$ and to any two drugs $1.8 \%$ to $15.8 \%$, which is higher resistance pattern over our observations [13].

Resistance to one or more drugs varies in a geographical area and depends on the treatment regiment used [13]. A study conducted in New York City during April 1991 has also shown that 33\% of the strains showed primary resistance to one or more antimycobacterial drugs [20]. Chavla and colleagues found an overall resistance of $30.9 \%$ in one or more drugs in Brooklyn [21].

The emergence of drug resistance in M. tuberculosis is an important adversary in Tuberculosis Control Programme. To assess the burden of drug-resistant strains in the community, surveillance programs must be planned. The drug against which maximum resistance is observed can be omitted from drug regimens. In the present study maximum resistance was observed to Rifampicin $(5.48 \%)$ followed by Isoniazid and Streptomycin (1.37\% each) among strains showing resistance to only one drug.

Global resistance rates show the initial resistance to Rifampicin 0 to $3 \%$ Isoniazid 0 to $16.9 \%$ and Ethambutol 0 to $4.3 \%$ [19].

Since the introduction of Rifampicin in the regimens of the National Tuberculosis Programme, resistance to Rifampicin are reported extensively. In 1992 Jain $\mathrm{NK}$ et al found initial resistance to Rifampicin as $0.6 \%$ in New Delhi, whereas from Gujarat no primary resistance to Rifampicin was reported
$[18,22]$.

Vasanthakumari et al have also reported an average of $2.3 \%$ resistance to Rifampicin [23]. Rifampicin resistance has increased as shown by Sophia $V$ et al with $2.6 \%$ [24].

As M. tuberculosis develops resistance by mutation, these resistant mutants to any single drug may be selected by not using an adequate combination of drugs. In the present study, 4 strains showed resistance to two drugs. All these strains showed resistance to Isoniazid and Rifampicin only, but not to other drugs. Only one strain showed resistance to three drugs i.e. Isoniazid, Rifampicin, and Streptomycin. According to Sophia $V$ et al, 7.4\% have shown resistance to two drugs among which resistance to Isoniazid and Streptomycin was more $(6.6 \%)$ as compared to Isoniazid and Rifampicin $(0.7 \%)[24]$.

Jindal SK et al has also shown high resistance to Isoniazid and Streptomycin (6.5\%) and resistance to Rifampicin and Isoniazid was 2-4\% [25]. Similarly, a surveillance report of tuberculosis in Tamilnadu has reported a 1 to $6 \%$ resistance to Isoniazid and Streptomycin. Literature studied shows that acquired resistance to Rifampicin individually or with other drugs is very high (50$70 \%$ ) which is an alarming situation as Rifampicin is extensively included in current regimens [13].

\section{Conclusion}

Treatment of tuberculosis with appropriate drugs for a defined period is an important factor in the complete remission of disease in the individual patient, as well as in the management of the disease in a community.

\section{What does the study add to the existing knowledge?}

There is a clear indication that resistance to Isoniazid alone does not readily affect the outcome of treatment but as soon as organisms develop resistance to Rifampicin also, there is a tremendous increase in treatment failure.

\section{Author's contribution}

All the authors, Dr. Virendra Kashetty, Dr. Mangala Ghatole, Dr. Apeksha Ghule were involved in the study design and conduct along with the manuscript preparation. 


\section{Reference}

01. World Health Organization. Global tuberculosis control- epidemiology, strategy, financing- WHO report 2009. World Health Organization. 2009. [Crossref]

02. Espinal MA, Laszlo A, Simonsen L, Boulahbal F, Kim SJ, Reniero $A$, et al. Global trends in resistance to anti tuberculosis drugs. N Engl J Med. 2001;344 (17)1294-1303.

doi:

[Article:https://doi.org/10.1056/nejm200104263441 706][Crossref]

03. Mitichson DA. Drug resistance in mycobacteria. Br Med Bull. 1984;40(1)84-90.

doi:

[Article:https://doi.org/10.1093/oxfordjournals.bmb. a071952][Crossref]

04. Tuberculosis research center [ICMR]. Chemotherapy of drug resistant tuberculosisThe tuberculosis research center experience over 40 years. Ind J Tub. $2000 ; 47 ; 201$.

[Crossref]

05. Gopi PG, Vallishayee RS, Appe Gowda BN, Paramasivan CN, Ranganatha S, Venkataramu $\mathrm{KV}$, Phaniraj BS et al. A tuberculosis prevalence survey based on symptoms questioning and sputum examinations. Ind J Tub. $1998 ; 44(4) 171-180$.

[Crossref]

06. Paramasivan CN, Bhaskaran K, Venkataraman $P$, Chandrasekaran V, Narayanan PR. Surveillance of drug resistance in tuberculosis in the state of Tamil Nadu. Indian Journal of Tuberculosis. 2000;47(1)27-33.

[Crossref]

07. Cohn DL, Bustreo F, Raviglione MC. Drug resistant tuberculosis- Review of the worldwide situations and SHO/IUATLD global surveillance project. Clin Infect Dis. 1997;24(1)121-130.

doi:

[Article:https://doi.org/10.1093/clinids/24.supplemen t_1.s121][Crossref]

08. WHO. (2002) Global Tuberculosis Control, Surveillance Planning, Financing. WHO Report. 2002.

Available at

[Article:https://apps.who.int/iris/bitstream/handle/10 665/42889/9241562641.pdf?sequence $=2$ ] [Crossref]
09. Paramasivan CN. An overview on drug resistant tuberculosis in India. Lung India. 1998;16(1)2128.

[Crossref]

10. Government of India (2002). Annual Report. DGHS, New Delhi. 2001-2002.

[Crossref]

11. Lwanga, Stephen Kaggwa, Lemeshow, Stanley and World Health Organization. Sample size determination in health studies- a practical manual / SK Lwanga and S Lemeshow. World Health Organization. 1991.

Available

at

[Article:https://apps.who.int/iris/handle/10665/4006

2][Crossref]

12. Macki and McCarney's. Practical Medical Microbiology. 13th Ed, Practical Med Microbiol. $1985 ; 2 ; 399$.

[Crossref]

13. Manual for laboratory technician. Revised National Tuberculosis Control Programme (RNTCP). DGHS, New Delhi. May 1999.

[Crossref]

14. Koch A, Vareldzis B, Styblo K. Multidrugresistant tuberculosis and its control. Res Microbiol. 1993;144(2)104-110.

doi: [Article:https://doi.org/10.1016/09232508(93)90023-u][Crossref]

15. World Health Organization. Laboratory evaluation of drug resistant tuberculosis, Document WHO/TB/93 171. Geneva, World Health Organization. 1993.

Available

at [Article:https://apps.who.int/iris/bitstream/handle/10 665/62460/WHO_TB_93.171.pdf][Crossref]

16. Kim S, Hong Y. Drug resistance of Mycobacterium tuberculosis in Korea. Tubercle and Lung Dis. 1992; 73(4)219-224.

doi:[Article:https://doi.org/10.1016/0962-8479

(92)90090-7][Crossref]

17. Chaulet P, Boulahbal F. Clinical Trial of a Combination of Three Drugs in Fixed Proportions in the Treatment of Tuberculosis; Groupe De Travail Sur La Chimiothérapie De La Tuberculose. Tuber Lung Dis. 1995;76(5)407412.

doi:[Article:https://doi.org/10.1016/0962-8479 (95)90006-3][Crossref] 
18. Trivedi SS, Desai SG. Primary anti-tuberculosis drug resistance and acquired Rifampicin resistance in Gujarat. India Tubercle. $1988 ; 69(1) 37-42$.

doi: [Article:https://doi.org/10.1016/00413879(88)90038-4][Crossref]

19. Neville K, Bromberg A, Bromberg R, Bonk S, Hanna BA, Rom WN. The third epidemicmultidrug-resistant tuberculosis. Chest. 1994;105(1)45-48.

doi: [Article:https://doi.org/10.1378/chest.105.1.45] [Crossref]

20. Chawla PK, Klapper PJ, Kamholz SL, Pollack AH, Heurich AE. Drug resistant tuberculosis in an urban population including patients at risk for human immunodeficiency virus infection. Am Rev Respir Dis. 1992;146(2)280-284.

doi:

[Article:https://doi.org/10.1164/ajrccm/146.2.280]

[Crossref]
21. Jain NK, Chopra KK, Prasad G. Initial and acquired Isoniazid and Rifampicin resistance to $M$ tuberculosis and its implications for treatment. Ind J Tub. 1992;39(2)121-124. [Crossref]

22. Singh M. Tuberculosis- Triumph and Tragedy. J Indian Med Assoc. 2003;101(3)190. [Crossref]

23. Sophia $V$, Balasangameshwara VH, Jagannatha PS, Kumar P. Initial drug resistance among tuberculosis patients under DOTS programme in Bangalore City. Ind J Tub. 2004;51;17-21. [Crossref]

24. Jindal SK. Drug resistance Tuberculosis India Clinical approach. Ind J Tub. 1995; 42;233. [Crossref]

25. Vasanthakumari R, Jagannath K, Rajasekarn S. Bacteriological status and prevalence of drug resistance in district tuberculosis centers in Tamil Nadu. Lung India. 1993;11(1-2)27-31. [Crossref] 